
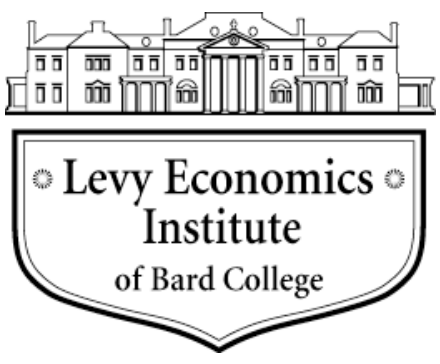

Working Paper No. 786

\title{
The Rational Expectations Hypothesis: An Assessment from Popper's Philosophy
}

by

\author{
Iván H. Ayala and Alfonso Palacio-Vera \\ Universidad Complutense de Madrid
}

January 2014

The Levy Economics Institute Working Paper Collection presents research in progress by Levy Institute scholars and conference participants. The purpose of the series is to disseminate ideas to and elicit comments from academics and professionals.

Levy Economics Institute of Bard College, founded in 1986, is a nonprofit, nonpartisan, independently funded research organization devoted to public service. Through scholarship and economic research it generates viable, effective public policy responses to important economic problems that profoundly affect the quality of life in the United States and abroad.

Levy Economics Institute

P.O. Box 5000

Annandale-on-Hudson, NY 12504-5000

http://www.levyinstitute.org

Copyright (C) Levy Economics Institute 2014 All rights reserved

ISSN 1547-366X 


\begin{abstract}
The rational expectations hypothesis $(\mathrm{REH})$ is the standard approach to expectations formation in macroeconomics. We discuss its compatibility with two strands of Karl Popper's philosophy: his theory of knowledge and learning, and his "rationality principle" (RP). First, we show that the REH is utterly incompatible with the former. Second, we argue that the REH can nevertheless be interpreted as a heuristic device that facilitates economic modeling and, consequently, it may be justified along the same lines as Popper's RP. We then argue that, our position as to the resolution of this paradox notwithstanding, Popper's philosophy provides a metatheoretical framework with which we can evaluate the REH. Within this framework, the REH can be viewed as a heuristic device or strategy that fulfils the same function as, for instance, the optimizing assumption. However, we believe that the REH imparts a serious methodological bias, since, by implying that macroeconomic instability is caused exclusively by "exogenous" shocks that randomly hit the economy, it precludes the analysis of any sources of inherent instability caused by the making of (nonrandom) errors by individuals, and hence it favors the creation of an institutional configuration that may be ill suited to address this type of instability.
\end{abstract}

Keywords: Popper; Knowledge; Rational Expectations; Learning; Trial; Error Elimination JEL Classifications: A12, B41, B50, D84 


\section{INTRODUCTION}

One of the most deeply entrenched ideas in Karl Popper's evolutionary epistemology is the analogy between the growth of scientific knowledge (and knowledge in general) and the evolutionary mechanism for 'natural' selection. The main point of Popper's analogy is that both the growth of scientific knowledge and the Darwinian biological mechanism are selection processes consisting of random trials followed by a subsequent process of error-elimination. In turn, the selection process is described as a two-step process, the first one consisting of the production of genetically different individuals, referred to as variation, and the second one consisting of selection proper whereby the 'fittest' individuals survive and successfully reproduce whereas the rest are gradually extinguished either through their demise or lower reproductive success. The key point is that Popper claims that this theory of biological evolution also applies to the growth of knowledge, that is, variation consists of the formulation of bold conjectures whereas the second step consists of their being subjected to rational criticism. In particular, and according to Popper, the method by which a solution is approached is fundamentally the method used by living organisms in the process of adaptation: the method of trial and error-elimination (Popper, 1963, p. 312). ${ }^{1}$ In turn, this raises the question what the theory of knowledge implicit in mainstream economic theory is and whether it is compatible with Popper's theory of the growth of knowledge. In this respect, Boland (2003) is almost alone to claim that the theory of knowledge and learning that is implicit in mainstream economics denoted as the 'conventional theory of knowledge and learning' (CTKL) - is utterly incompatible with Popper's theory of knowledge and learning owing to its inductive basis. The standard approach to modelling economic agents' expectations in mainstream macroeconomics, the 'rational expectations hypothesis' (hereafter REH), is a clear example of a theory that implicitly assumes that human knowledge is acquired inductively and through a learning process which presupposes a pre-existing and highly stable reality which can be successfully disclosed by economic agents. ${ }^{2}$ Either way, we will show that the REH is at odds with Popper's theory of knowledge and learning. To be sure, the latter delivers a fatal blow to induction and

\footnotetext{
${ }^{1}$ Notwithstanding it, Bradie (1986) recognizes that Popper's reconciliation of the non-progressive nature of biological evolution with the alleged progressive character of science is an uneasy one.

${ }^{2}$ Woodford (2009) argues that there has been convergence of views in macroeconomics over the last two decades and that such convergence is characterized primarily by a cessation of methodological struggles within macroeconomics. According to him, the REH is one key element of the New Synthesis.
} 
presupposes indeterminism and imperfect adaptation to the surrounding environment, all of which are anathema to the REH.

That said, it could be argued that Popper's methodological prescription for the social sciences known as 'situational analysis' (of which the 'rationality principle' is a component) was prompted precisely by his becoming acquainted with the methodology of neoclassical microeconomics and that, notwithstanding our alleged incompatibility of his theory of knowledge and learning with the REH, one could advocate the REH on the basis that, as with the optimization assumption in mainstream economics, the former can be justified along the same reasons that Popper and subsequent commentators have expressed in support of his 'rationality principle'. At this juncture, one possibility is to suggest that there is an inconsistency in Popper's philosophy in that his 'rationality principle' is incompatible, at least if it is identified with optimization, with his theory of knowledge and learning. However, we do not pursue this line of argument in this paper. Rather, the argument we develop in this paper is that the combination of Popper's theory of knowledge and learning with its accompanying notions of imperfect adaptation and indeterminism and his 'situational analysis' constitutes a metatheoretical framework that can help us evaluate the REH comprehensively. As it will emerge, the REH is properly viewed as a heuristic device which provides a 'closure' to macroeconomic models and which may have served to its original purpose of helping theorists develop equilibrium analysis. Yet, and notwithstanding the former, we will also argue that this alleged advantage has come at the expense of lack of realism in macroeconomic models by ignoring the key problem of how economic agents acquire knowledge and, above all, neglect of those alternative approaches in which growth and macroeconomic instability are endogenouslygenerated phenomena which stem ultimately from economic agents' mistakes in the aftermath of decisions made under 'uncertainty' in the sense of John Maynard Keynes and Knight.

The content of this paper is as follows. The following section contains a review of Popper's evolutionary theory of knowledge and learning. In section 3, we expound the REH. In section 4, we assess the REH in light of Popper's Darwinian evolutionary epistemology. In section 5, we expound Popper's methodological proposal for the social sciences known as 'situational analysis'. In section 6, we argue that the combination of Popper's theory of knowledge and learning and 'situational analysis' provides a suitable meta-theoretical framework for the evaluation of the costs and benefits of using the REH in macroeconomic modelling. Finally, section 7 summarizes and concludes. 


\section{POPPER'S THEORY OF KNOWLEDGE AND LEARNING}

Inductive inference is reasoning from the past observed behaviour of objects to their future behaviour. The 'problem of induction' was originally raised by David Hume (1748) who pondered whether inductive evidence can go beyond the available evidence in order to predict future events. Past evidence, he argued, can tell us about past experience only. If we wish to go beyond this, we will surely be on dubious ground. Hume's main argument was that we cannot rationally justify the claim that nature will continue to be uniform merely because it has been in the past, as this is using the sort of reasoning (induction) that is under question, i.e., it would be circular reasoning. Hume also noticed that we tend to believe that phenomena behave in a regular fashion, i.e. that patterns in the behaviour of objects tend to persist into the future. Popper defines the philosophical 'problem of induction' as the problem of providing a justification for the belief that the future will be (largely) like the past (Popper, 1972, p. 2). He identifies two main problems in Hume's criticism of induction: (i) a logical problem $\left(H_{L}\right)$, and (ii) a psychological problem $(H P)$. First, Hume's $H_{L}$ is whether we are justified in reasoning from repeated instances of which we have some experience to other instances of which we have no experience. Hume's answer to $H_{L}$ is negative no matter how lengthy the number of repetitions. Second, Hume's $H P$ is why, nevertheless, all reasonable people believe that instances for which they have no experience at all will conform to those for which they have experience. Hume's answer to $H P$ is that 'the psychological mechanism of association forces them to believe, by custom or habit, that what happened in the past will happen in the future' (Popper, 1972, p. 90). According to Popper, this would explain why Hume gave up rationalism and looked at man not as endowed with reason but as a product of blind habit. By contrast, Popper argues that there is no such thing as induction by repetition either in psychology or science:

'We do not act upon repetition or "habit", but upon the best tested of our theories which... are the ones for which we have good rational reasons; not of course good reasons for believing them to be true, but for believing them to be the best available from the point of view of a search for truth or verisimilitude... The central question for Hume was: do we act according to reason or not? And my answer is: Yes.' (op. cit., p. 95)

Popper restates Hume's problem of induction in the following way. First, he denies that a theory can be simply justified by assuming the truth of certain observation statements. Rather, he insists that all theories are hypotheses and, hence, they can be overthrown (op. cit., p. 13). 
Further, he states that paradoxically induction is inductively invalid, that is, the claim that induction is a legitimate way to acquire (true) knowledge needs to be supported by a 'higher' principle that has, in its turn, been established inductively. But this strategy ultimately leads us into an infinite regress insofar as we will endlessly have to resort to a superior principle that has been discovered through induction. Second, he offers the proposition that the claim that an explanatory universal theory is false can be justified by the truth of certain observation statements (op. cit., p. 7). As the typical example goes, no matter how many white swans we come across, the finding of just one black swan will lead to the rejection of the universal statement 'all swans are white'. Consequently, he encourages scientists to construct severe tests that help detect any false theory among the set of non-refuted ones so that, by a method of elimination, they may eventually hit upon a true theory even though the method itself can never establish its truth (op. cit. pp. 14-15). ${ }^{3}$ Thus, he argues there is an asymmetry between verification and falsification by experience; any conjecture may be true or false - but even if it turns out to be true, there is no way we can ever prove it (op. cit., p. 12). The method of science, according to Popper is, hence, 'the method of bold conjectures and ingenious and severe attempts to refute them' (op. cit., p. 81). Since all theories involve universal statements, we can only 'learn' by proving that our knowledge is false. Specifically, learning takes place either when we reject one's prior theory or when we are forced to adjust one's theory in a way that recognizes that in its prior version it was false (op. cit., p. 81). As Boland (2003, p. 242) notes, an implication of Popper's theory of learning is that the accumulation of information does not increase the likelihood that our theories are true because all we can 'learn' from experience is that our theories are false.

Third, Popper argues that theories are genetically incorporated into all our sense organs and this predisposes us to discriminate a priori between relevant or absorbable input and input that can be ignored (op. cit., p. 72). For instance, sense organs like the eye only react to those selected environmental events which they 'expect'. However, according to him, this prior knowledge cannot be the result of observation; it must be the result of adaptation to the surrounding environment by trial and error. He writes that 99 percent of the knowledge of all living organisms is inborn and incorporated into our biochemical constitution (Popper, 1990, p. 46). Furthermore, he claims that there is no theory-free language to help us interpret data

\footnotetext{
${ }^{3}$ Popper adopted Tarski's theory that truth is correspondence with the facts or with reality (Popper, 1972, p. 44).
} 
because myths or primitive theories emerge together with language. Thus, there is never pure perception since all languages are theory-impregnated (op. cit., p. 145). This leads him to reject any epistemology which chooses our 'direct' observations and perceptions as the starting point; the fact that theories are built into our sense organs implies that 'the epistemology of induction breaks down even before taking its first step' (op. cit., p. 146). Instead, he proposes his own theory of knowledge and learning:

'All acquired knowledge, all learning, consists of the modification (possibly the rejection) of some form of knowledge, or disposition, which was there previously, and in the last instance of inborn dispositions... Because all our dispositions are in some sense adjustments to invariant or slowly changing environmental conditions, they can be described as theory-impregnated' (op. cit., p. 71).

Fourth, Popper's rejection of Hume's inductive theory of the formation of beliefs leads him to propose the conjecture that 'logical' considerations may legitimately be transferred to 'psychological' considerations. He argues that not only do we reason rationally and thus contrary to the principle of induction which was declared invalid by Hume, but we also behave rationally. By applying this conjecture to human psychology he arrives at the method of trial and error-elimination. In this method, the trials correspond to the formation of competing hypotheses whereas the elimination of errors corresponds to the refutation of (false) theories. In other words, he proposes the theory that individuals do not think in an inductive way but form their beliefs by eliminating false theories. He labels this the 'principle of transference' (op. cit., p. 6). As a result of it, the theory of knowledge and learning that emerges from Popper's solution to the 'problem of induction' is clearly evolutionary:

'Some of the errors that have entered the inheritable constitution of an organism are eliminated by eliminating their bearer; that is, the individual organism. But some errors escape, and this is one reason why we are all fallible: our adaptation to the environment is never optimal, and it is always imperfect' (Popper, 1990, p.47, emphasis added).

In this respect, Popper asserts that no equilibrium state of adaptation is reached by the application of the method of trial and error-elimination since (i) no optimal trial solution to any particular problem is likely to be offered, and (ii) the emergence of new structures and instructions involves a continuous change in the environmental situation (Popper, 1994, p. 4). Lastly, Popper views the growth of knowledge as lacking any ultimate intent or purpose as in evolutionary biology which leads him to adopt a radical indeterminism: 
'In our changing world, the situation and, with it, the possibilities, and thus the propensities, change all the time. They certainly may change if we, or any other organisms, prefer one possibility to another; or if we discover a possibility where we have not seen one before. Our very understanding of the world changes the conditions of the changing world; and so do our wishes, our preferences, our motivations, our hopes, our dreams, our fantasies, our hypotheses, our theories. Even our erroneous theories change the world, although our correct theories may, as a rule, have a more lasting influence. All this amounts to the fact that determinism is simply mistaken' (Popper, 1990, p. 17).

In short, Popper (1990) makes clear that the past affects but does not determine the future, that is, the future is not pre-determined or fixed in advance. As we will argue below, this position is in conflict with the REH since the latter logically implies that there is a pre-existing world or reality that is independent of economic agents' decisions and actions.

\section{THE RATIONAL EXPECTATIONS HYPOTHESIS}

The REH is the most popular approach to modelling expectations in mainstream economics. ${ }^{4}$ The REH can be viewed as an attempt to provide neoclassical economics with a theory of expectations and beliefs formation that is a priori consistent with the optimization hypothesis. We owe its original formulation to Muth (1961) who suggests that expectations should be modelled in a way that allows them to change endogenously when the structure of the system changes:

'I should like to suggest that expectations, since they are informed predictions of future events, are essentially the same as the predictions of the relevant economic theory... The hypothesis can be rephrased a little more precisely as follows: that expectations of businesses (or, more generally, the subjective probability distribution of outcomes) tend to be distributed, for the same information set, about the prediction of the theory (or the “objective” probability distributions of outcomes)' (Muth, 1961, p. 316).

\footnotetext{
${ }^{4}$ This is so in spite of having been criticised by some outstanding theorists including several Nobel Prize Awards in Economics like Arrow (1978), Tobin (1981), Krugman (2009), and Stiglitz (2011). Likewise, Soros (2009, p. 6) argues that 'rational expectations theory is no longer taken seriously outside academic circles'. Machlup (1983, p. 174) protests about the use of the term 'rational' expectations since, according to him, rationality means consistency with one's preconceptions and prejudgments, no matter whether they are right or wrong. He then suggests that a more adequate term is 'correct' expectations in the sense of being in accordance with the expectations of neoclassical theorists. He defines (op. cit., p. 172) the process whereby the plans and courses of action pursued by all agents become mutually compatible under the REH as a process of compulsory learning.
} 
Therefore, according to Muth (op. cit.), the REH implies that economic agents' subjective expectations are, on average, equal to the true values of the variables. ${ }^{5}$ In other words, it is only the average of economic agents' forecasts that will be equal to the mathematical expectation of the variable. Thus, the forecast of a given individual may not coincide with the latter. ${ }^{6}$ However, as Knudsen (1993, p. 153) rightly observes, the reintroduction of the REH by Lucas in 1972 entailed a reinterpretation of it. In particular, the REH was now reinterpreted as an extension of the old Marschak-Stigler optimizing assumption to the collection of information to the formation of expectations as it now implied that the expectations of every single agent were correct on average. As noted in Sargent (1993, p. 3), the former means that the REH imposes two requirements on economic models: 'substantive' rationality and mutual consistency of perceptions about the environment. ${ }^{7}$ Hence, the REH can be seen as providing a 'system-closure' to economic models in that it makes the process of expectations formation endogenous to them. ${ }^{8}$ By doing so, neoclassical economics has come full circle. For the purposes of this essay, the key point is that the REH is perceived by one of its qualified practitioners as requiring a high degree of stability and regularity over time of the phenomenon under study:

'Evidently, this hypothesis [Muthian rationality] will not be of value in understanding psychotic behaviour. Neither will it be applicable in situations in which we cannot guess which, if any, observable frequencies are relevant: situations which Knight called "uncertainty". It will most likely be useful in situations in which the probabilities of interest concern a fairly well defined recurrent event, situations of "risk" in Knight's

\footnotetext{
${ }^{5}$ Hayek (1937) describes the 'perfect foresight' assumption in neoclassical economics (the deterministic version of the REH) as follows:

'There would of course be no reason why the subjective data of different people should ever correspond unless they were due to the experience of the same objective facts. But the point is that pure equilibrium analysis is not concerned with the way in which this correspondence is brought about. In the description of an existing state of equilibrium which it provides, it is simply assumed that the subjective data coincide with the objective facts' (Hayek, 1937, p. 43, emphasis added).

${ }^{6}$ However, Muth (1961, p. 317) notes that, for the purpose of analysis, he focuses on a 'specialized' or restrictive form of the REH where it is assumed that: (i) the random disturbances that hit the economy are normally distributed, (ii) certainty equivalence holds for all the variables that are to be forecast, and (iii) the equations of the system are linear.

${ }^{7}$ Simon (1976, p. 130) identifies human behaviour as being substantively rational 'when it is appropriate to the achievement of given goals within the limits imposed by given conditions and constraints'.

${ }^{8}$ For instance, Arrow (1986, p. S394) characterizes the REH as a stochastic form of the 'perfect foresight' assumption.
} 
terminology... In cases of uncertainty, economic reasoning will be of no value... Insofar as business cycles can be viewed as repeated instances of essentially similar events, it will be reasonable to treat agents as reacting to cyclical changes as "risk", or to assume their expectations are rational' (Lucas, 1977, p. 15, term in brackets and emphasis added).

Thus, the REH presumes that the phenomenon under study exhibits sufficient stability and regularity over time as to allow economic agents to infer its stylized facts and attach probabilities to an exhaustive list of known alternative outcomes. In this respect, Lucas's position coincides with that of Savage (1954), the founder of modern Bayesian decision theory who defines 'small worlds' as situations of perfect knowledge where all alternatives, their consequences, and their probabilities are known for certain. Examples of 'small worlds' are hazard games such as lotteries and roulette. According to him, these are the type of environments in which the application of Bayesian decision theory is legitimate. By contrast, he defines 'large worlds' as those environments where part of the needed information is missing or where the future is 'uncertain' in the sense of Keynes (1920), Knight (1921), and GeorgescuRoegen (1971). Crucially, Savage (op. cit., p. 16) makes it clear that applying Bayesian theory to decisions in 'large worlds' is 'utterly ridiculous' because there is no way to know all the alternatives, consequences, and probabilities.

Next, the regularity and predictability of economic phenomena that Lucas (op. cit.) presents as the condition to be met for the emergence of (neoclassical) economic reasoning implies that the environment in which decisions are made must be ergodic so that economic agents can confidently extrapolate into the future the regularities inferred from the past. An ergodic environment exhibits the property that 'averages calculated from past observations cannot be persistently different from the time average of future outcomes' (Davidson, 1991, p. 132). Such property is deemed by Samuelson (1969, p. 184) the 'sine qua non of the scientific method in economics'. Therefore, Lucas (1977) contemplates the possibility that some economic phenomena are non-ergodic albeit he argues that economic analysis should solely be concerned with ergodic worlds. The question whether the environments where economic agents typically make decisions happen to be ergodic is thus a crucial one. Most mainstream economists tend to assume that this is the case. By contrast, some Keynesian economists 
(Shackle, 1972; Davidson, 1991) insist that many economic decisions (like investment in capital equipment) are made in a non-ergodic environment. ${ }^{9}$

Lucas's reference in the previous quotation to 'repeated instances of essentially similar events' suggests that, at least initially, he had in mind an inductive theory of knowledge acquisition or learning. However, an inductive learning theory is necessarily grounded on a 'cumulative' theory of knowledge. In this respect, Boland (2003) argues that the theory of knowledge implicit in modern mainstream economics is based on a 'cumulative' view of knowledge and an inductive theory of knowledge acquisition or learning. The latter implies that, as the amount of information collected increases over time, the probability that our hypothesis is true increases and converges asymptotically to unity. Now, as Boland (op. cit.) insists, both the 'cumulative' theory of knowledge and the inductive theory of learning are at odds with Popper's philosophy. According to Popper, all knowledge is conjectural and, hence, no matter how much (finite) favourable empirical evidence is accumulated, the likelihood of a certain hypothesis being true does not increase. However, Lucas (1986) has apparently adopted a somewhat different theory of learning later on. Specifically, when justifying the optimization assumption in economics he characterizes the type of situations on which economic theory focuses as the end-result of a 'learning' process:

'Economics has tended to focus on situations in which the agent can be expected to "know" or to have learned the consequences of different actions so that his observed choices reveal stable features of his underlying preferences... Technically, I think of economics as studying decision rules that are steady states of some adaptive process, decision rules that are found to work over a range of situations and hence are no longer revised appreciably as more experience accumulates...' (Lucas, 1986, p. 218, emphasis added).

This quotation reveals some features of Lucas's later methodological approach which are not present in Lucas (1977). First, he still seems to adopt a 'cumulative' theory of knowledge as he refers to the accumulation of experience over time. Second, he suggests that the decision rules neoclassical economic theory deals with, namely, those decisions rules that stem from the implementation of optimization methods can be interpreted as steady states of some adaptive learning process. Although he does not dwell on it, the latter presumably consists of a trial and

\footnotetext{
${ }^{9}$ Likewise, Volz and Gigerenzer (2012, p. 1) claim that 'decision making under uncertainty is what our brain does most of the time, while situations of known risk are relatively rare and found mostly in gambling'.
} 
error-elimination learning process whereby economic agents make decisions which may then turn out to be right or wrong so that by discarding the bad decision rules and retaining the good ones economic agents manage to 'learn'. ${ }^{10}$ Lastly, he suggests that the learning process eventually converges to a steady state. ${ }^{11}$ He then implies that economic theory should be concerned solely with those decision rules that economic agents have adopted once the 'true' model has been found, the implicit assumption being that decisions made prior to the discovery of the 'true' model do not have any repercussions in the economy, that is, they do not alter the 'true' model. In other words, the 'true' model is pre-determined or exists prior to decisions made by economic agents. Arguably, this aspect of the learning process presented in Lucas (1986) is closely linked to the ergodicity assumption in that a pre-existing reality that is independent of economic agents' beliefs, decisions, and actions implies determinism and this, in turn, can only be compatible with an ergodic environment. Such learning process apparently exhibits some resemblance to Popper's Socratic theory of knowledge and learning insofar as it is adaptive. However, as we will argue below, when the former is subject to closer scrutiny the similarity turns out to be only superficial.

\section{IS THE RATIONAL EXPECTATIONS HYPOTHESIS COMPATIBLE WITH POPPER'S EVOLUTIONARY THEORY OF KNOWLEDGE AND LEARNING?}

We now address the question of the compatibility or otherwise of the REH with Popper's evolutionary theory of knowledge and learning. As we intimated above, it appears as if the $\mathrm{REH}$, provided our interpretation of Lucas's views are valid, presumes that economic agents acquire knowledge through an adaptive learning process. In turn, we argued that the latter necessarily requires the implementation of a trial and error-elimination mechanism. Whether the formation of REH relies on an adaptive trial-and-error mechanism or on a simple extrapolating mechanism is not, however, essential to our argument yet assuming the former rather than the

\footnotetext{
${ }^{10}$ For instance, the argument by Sargent (1993) and several subsequent authors that a RE equilibrium can be interpreted as the ultimate outcome of a learning process presupposes either that the world is ergodic and that the learning process is not imperfect in the sense of Popper. By contrast, Arrow (1986) rejects the idea that the assumption of 'substantive' rationality that pervades neoclassical theory can be interpreted as the outcome of a process of learning and adaptation.

${ }^{11}$ Tversky and Kahneman (1986, p. 90) note that a learning process may well help improve the overall efficiency of the decision-making process yet they argue that effective learning (in Lucas' sense) can only take place under special conditions. In particular, the former requires both accurate and rapid feedback about the relation between the situational condition and the appropriate response. They argue that such conditions rarely arise in practice.
} 
latter may help clarifying the differences between the REH and Popper's Socratic theory of knowledge and learning. That said, we will argue below that the nature of the learning mechanism implicit in the REH differs substantially from Popper's in, at least, the following three respects.

\subsection{Conjectural Knowledge}

The cumulative character of the theory of knowledge implicit in the REH entails that, as the amount of information collected increases over time, economic agents will improve their forecasts so that, if a sufficient (finite) amount of information is collected, one can conceive that they will eventually be capable of producing economic forecasts exhibiting negligible standard errors. Arguably, such scenario is tantamount to the 'steady state' Lucas (1986) refers to in the quote above in which economic agents do not need to revise their decision rules further.

However, if they do not need to revise their decision rules any further, then this must be because their forecasting ability can not be improved significantly by collecting additional information and this, in turn, will only be the case if they have managed to find the 'true' model of the economy, i.e. the model that produces unbiased estimates. Thus, the learning process whereby economic agents revise the tentative models they use to formulate predictions in the wake of observed discrepancies between expected and realized outcomes is assumed to converge eventually to a steady state in which expectations are 'rational'.

The first problem such an adaptive learning process encounters when scrutinized in the light of Popper's Socratic theory of knowledge and learning is that the learning process that supposedly allows economic agents to select the 'true' model runs counter to Popper's views. As we explained in section 2 above, Popper's theory of knowledge and learning implies that we can never know whether a given hypothesis is 'true' and, hence, the assumption that economic agents get to know the 'true' model is fallacious in, at least, the two following respects. First, if we follow Popper no matter how many tentative models are tested and subsequently replaced, there is simply no way we can get to know whether the model we are using for predictive purposes (even if it happens to be right one) is 'true'. This is not only because there is no inductive logic but also because, as Popper insists, any theoretical model is always an oversimplification of reality and, hence, false (Popper, 1994, p. 166). Consequently, all we can achieve (if we are skilful enough) is to end up with a model that produces 'better' estimates than other models in a particular historical and institutional context — and even this may be rather 
hard to achieve due to the problems posed by the Duhem-Quine thesis — but this by no means implies that our model is 'true'. Second, if we assume that individual forecasts are unbiased on average this logically implies that agents do not make systematic errors. Rather, the errors they make (if they make any at all) will be random and, hence, they will not be able to 'learn' anything from them. As we explained above, Popper's theory of knowledge implies that we 'learn' by correcting our errors. To be sure, error-elimination requires that expected outcomes diverge significantly, and in a non-random fashion, from realized ones. Yet, the REH precludes any error-elimination mechanism because it implies that, on average, individuals do not make errors! ${ }^{12}$ In other words, the REH does not incorporate any trial and error-elimination device that allows individuals to 'learn'.

\subsection{Imperfect Adaptation}

A second problem with the characterization of the REH as based on an adaptive learning process is that the latter is assumed to converge eventually to a steady state in which expectations are optimal or 'rational'. However, such characterization of learning runs counter to Popper's philosophy. To be sure, Popper makes clear that the process of adaptation to the surrounding environment is often successful and often unsuccessful. In particular, some errors will inevitably escape and this possibility is the main reason why we are all fallible (Popper, 1990, p. 47). Consequently, Popper (1994, p. 4) argues that the systematic application of the method of trial and error-elimination can not result in an 'optimum' adaptation to the surrounding environment. Instead, and due to the partial elimination of errors, our adaptation to the environment is always imperfect. It follows from this that the observed states of adaptation can never be the result of convergence to an optimum. Should all errors be purged, and provided the surrounding environment remains constant throughout, the process of adaptation to the latter could eventually be perfect. At that point, and only then, the state of adaptation could be interpreted as the outcome of a process of convergence to an optimum. In such scenario, human fallibility would exist only to the extent that changes in the surrounding environment can not be predicted in advance. By contrast, as we explain below, Popper's theory of knowledge and learning implies that out errors may stem either from the occurrence of exogenous random

\footnotetext{
${ }^{12}$ Under the REH forecast errors stem only from the occurrence of exogenous random shocks since the model that generates forecasts is assumed to coincide with the 'true' model.
} 
shocks - as in the case of the REH — or, alternatively, from the fact that the tentative model we rely on to formulate expectations may be false.

\subsection{Non-determinism}

The third and final aspect of the REH we should like to address is closely related to its ontological domain. The latter is made explicit in Lucas (1977, p. 15) when he argues that Muthian rationality 'will most likely be useful in situations in which the probabilities of interest concern a fairly well defined recurrent event, situations of "risk" in Knight's terminology". As we noted above, situations of 'risk' correspond to environments in which individuals can infer the empirical regularities observed in the past and extrapolate them into the future. Further, we suggested above that the adaptive learning process that Lucas (1986) seems to have in mind implies that the surrounding environment is ergodic since it is (implicitly) assumed that any actions undertaken by economic agents during the adaptive learning process and thus before their expectations become 'rational' do not affect the future path of the economy.

We showed in section 2 above that Popper rejects determinism. It is somehow a matter of speculation whether Popper would have subscribed to the 'non-ergodicity' thesis in the context of the social sciences. To the best of our knowledge, he does not mention the term ergodic yet he wholeheartedly embraces 'indeterminism' in the physical world. Specifically, he explains that statistical averages will exhibit a tendency to remain stable only if the physical conditions remain stable (Popper, 1990, p. 12) which suggests that he would accept the ergodicity assumption in the social sciences only if the premise that 'social' conditions remain sufficiently stable over time is sensible. We can only guess. He makes 'indeterminism' in the physical world the very basis of his 'propensity theory of probability' which is an objective interpretation of the theory of probability as opposed to the subjectivist theory of probability advocated by Heisenberg and Einstein in physics and by Keynes, Ramsey, and De Finetti in the social sciences. According to Popper's interpretation, propensities are real forces that stem from physical realities and which change all the time:

'With the introduction of propensities, the ideology of determinism evaporates. Past situations, whether physical or psychological or mixed, do not determine the future situation. Rather, they determine changing propensities that influence future situations without determining them in a unique way... Quite apart from the fact that we do not know the future, the future is objectively not fixed. The future is open: objectively open' (Popper, 1990, pp. 17-18). 
Thus, it is clear that, for Popper, the world is 'non-deterministic' (Popper, 1990, p. 25). In turn, he defines a 'deterministic' world as one where there is 'no room for human decision' (Popper, 1990, p. 7). It is such 'deterministic' world that, according to us, is implicit in the $\mathrm{REH}$. To be sure, if the actions undertaken by economic agents during the learning process before their expectations become 'rational' are not allowed to affect the internal structure of the REH equilibrium prevailing in the 'steady state' then the latter must necessarily exist prior to the start of the learning process. In other words, if the actions of economic agents affected the structure of the REH equilibrium, then any action undertaken by anyone would trigger a process of revision of expectations by every individual in light of the observed changes in the structure of the economy. The ensuing iterative process could potentially be endless since there is no guarantee a priori that it would eventually converge to a steady state. In short, the REH implies that the world is deterministic insofar as it does not take full account of human choice.

Now, a deterministic world is, by and large, ergodic. ${ }^{13}$ As Crotty (1994, p. 108) puts it, the structure of an ergodic stochastic economic model will not be affected by the particular choices of economic agents and, hence, the outcomes of the model must be independent of agent choice. In other words, the model does not exhibit hysteresis or path-dependency. An example of an ergodic stochastic model in which the distribution of outcomes is pre-given and, hence, independent of agents' decisions, is the distribution of daily hours of daylight in a city. The latter will be fully independent of agents' errors and their decisions about whether or not to wear sunglasses. Thus, to the extent that the REH implies that the underlying stochastic processes are pre-given, it is essentially 'restricted to a world in which agents' decisions do not "create" the future' (op. cit.), i.e., an ergodic world. To sum up, the REH stands in stark contrast to Popper's radical indeterminism according to which 'our very understanding of the world changes the conditions of the changing world; and so do our wishes, our preferences, our motivations, our hopes, our dreams, our fantasies, our hypotheses' (Popper, 1990, p.17). This leads to the question whether there is any scope for justifying the REH in the context of Popper's philosophy. In the following section, we will expound Popper's Rationality Principle (hereafter RP) and discuss the possibility of interpreting the REH as a heuristic device or research strategy.

\footnotetext{
${ }^{13}$ By contrast, a non-deterministic world may be ergodic or non-ergodic. For instance, Watkins (1974, p. 384) argues that Popper's propensity interpretation of probability implies that indeterminacy may a priori be compatible with orderliness.
} 


\section{POPPER'S METHODOLOGICAL PROPOSAL FOR THE SOCIAL SCIENCES}

In his autobiography Popper makes clear that his methodological proposal for the social sciences stems from an 'attempt to generalize the method of economic theory (marginal utility theory) so as to become applicable to the other theoretical social sciences' (Popper 1976, pp. 117-8). As a result of it, some mainstream economists have invoked the RP as providing a philosophical foundation for the use of the optimization assumption in economics. However, and to the best of our knowledge, advocates of the REH have not explicitly referred to the RP to justify the former. According to Popper, there is no fundamental difference between the natural sciences and the social sciences since both of them resort to the construction of models or typical problem-situations to both explain and predict events. ${ }^{14}$ If anything, models are viewed as being even more important in the social sciences due to the non-existence of universal laws. Yet, he makes it clear that such models are an over-simplification of reality and, hence, they do not represent the facts truly. He adds that the essential problem of the social sciences is 'to explain and understand events in terms of human actions and social situations' (Popper, 1994, p. 166). In turn, the reconstruction of social situations will include the consideration of all the relevant 'social institutions' which Popper defines as 'all those things which set limits or create obstacles to our movements and actions' (op. cit., p. 167).

Next, Popper makes a distinction between 'rationality' as a personal attitude and his RP. The former is defined as the attitude of readiness to discuss one's beliefs in a critical way and to correct them if they turn out to be wrong so that 'rational' behaviour is, presumably, that type of behaviour which is consistent with his evolutionary theory of knowledge and learning. By contrast, the RP has nothing to do with the assumption that men adopt a rational attitude. Rather, it is an a priori methodological principle which assumes that our actions are adequate to our problem-situations as we see them (Popper, 1994, p. 181). ${ }^{15}$ According to this principle,

\footnotetext{
${ }^{14}$ This thesis is known as methodological monism.

${ }^{15}$ Early presentations of the method of 'situational analysis' can be found in Popper's Open Society, vol. 2, chapter, 14, especially p. 97, in his Poverty of Historicism, sections 31 and 32, and in Popper (1972, p. 179). Notably, as Koertge (1975) remarks, Popper's views on the 'rationality principle' have evolved over time. As time passed by, Popper tended to weaken his claims about the kinds of actions that agents could be expected to perform so 'where he had earlier spoken of actions as being "rational" or "appropriate", he now tended to characterize them as "adequate", or "adapted", or "in accordance with" the situation' (op. cit., p. 441). Koertge adds that the most likely reason for this evolution in terminology was his increasing emphasis on the fact that the situation which played a central role in the explanation was not the agent's objective physical-psychological situation but the agent's theory of his own situation or the situation as the agent saw it (Koertge, 1975, p. 442).
} 
explanations of human behaviour should proceed as follows (Koertge, 1975; Hands, 1992). Let us assume the problem is to explain why individual $A$ adopted a certain type of behaviour, say $X$. The first step (step I) is to describe the 'situation' of individual $A$ at the time the behaviour in question $(X)$ was adopted. As Hands (1992) explains, such description will usually include both subjective elements (like preferences, beliefs and desires) as well as objective elements (like physical, technological, and social constraints). The second step (step II) is to provide an analysis of the problem-situation. The third step (step III) of the explanation of human behaviour is to add the RP. The final step consists of the explanandum, i.e., that $A \operatorname{did} X$. In the case our objective is to explain an observed phenomenon, the RP is 'brought up' when we connect the analysis of the situation with the phenomenon to be explained.

As Koertge (1975, p. 443) points out, the RP actually consists of two clauses: the first $(R P-1)$ says that 'every action (by a person) is a rational response to some problem-situation' whereas the second $(R P-2)$ tells us that 'every person in a problem-situation responds rationally to it'. In turn, RP-1 entails: (i) that the response was issued through a methodical appraisal of the set of possible solutions available to the actor, (ii) that a description of the problem-situation and the appraisal process could be verbalized by the actor, and (iii) that the person acted as he did as a result of the appraisal process so that if a better alternative had been available to him he would have taken it. Therefore, the complete RP as reformulated in Koertge (op. cit.) emphasizes the connection between the action and the systematic deliberation process from initial conditions that made the individual behave as he did. Crucially, Koertge (1979, p. 92) insists that, for Popper, to explain an action using the RP does not 'imply that the agent's beliefs are reasonable nor even that his method of making decisions is the best possible one'. Rather, it only presupposes that the individual assessed the situation in a systematic way.

According to Popper, in the social sciences the RP plays a role that is analogous to the universal laws of the natural sciences. More precisely, the RP is an animation principle which plays a role in the context of 'situational analysis' similar to that of Newton's Laws in the explanation of motions within the solar system (Popper, 1967, p. 144). However, he makes it clear that the RP is not true insofar as it is an over-simplification: 'The rationality principle is false. I think there is no way out of this. Consequently, I must deny that it is a priori valid' (op. 
cit., p. 361). ${ }^{16}$ Yet, he believes it represents a good approximation to the truth. Therefore, the RP 'does not play the role of an empirical explanatory theory, of a testable hypothesis' (op. cit., p. 360). Rather, he views it as an integral part of every testable theory. Specifically, he proposes to avoid blaming it whenever our theory breaks down in the aftermath of empirical tests. His methodological advice to social scientists is thus never to abandon the RP so that, in the wake of an empirical refutation of their model, they should always revise their models of the agent's situation. He offers two arguments in favour of this strategy: (i) that we learn more if we blame our situational model, and (ii) that the adoption of such principle 'reduces considerably the arbitrariness of our models' (op. cit., p. 362). As for the first argument, he explains that:

'The main argument in favour of this policy is that our model is far more interesting and informative, and far better testable, than the principle of the adequacy of our actions. We do not learn much in learning that this is not strictly true: we know this already.' (Popper, 1985, p. 362)

Likewise, Caldwell (1991, p. 25) argues that, although immunizing stratagems should be avoided 'at least in the special case of situational analyses, one is able to criticize more severely and obtain fruitful criticisms if one blames the model rather than the rationality principle whenever a falsification occurs'. As for the second argument, Popper explains that:

'The attempt to replace the rationality principle by another one seems to lead to complete arbitrariness in our model-building. And we must not forget that we can test a theory only as a whole, and that the test consists in finding the better of two competing theories which may have much in common; and most of them have the rationality principle in common' (Popper, 1985, p. 362).

As Hands (1985, p. 87) notes, Popper's first argument means that if we are to be consistent with the RP, 'the falsification of a specific theory only means that we have misspecified the "situation", i.e. we have attributed the wrong preferences or constraints to the individual'. In turn, Popper's second argument implies that, although the RP is a priori falsifiable, we choose to make a methodological decision that, when faced with a falsifying observation, we will stick to it and revise instead our hypotheses about the desires, beliefs and

\footnotetext{
${ }^{16}$ Of course, this applies to any premise aimed at providing a 'closure' for a model. As Loasby $(1999$, p. 14) aptly notes 'all closures are in some degree false. There can be no self-sufficient Cartesian scheme for deducing justified true knowledge from some original certainty'.
} 
constraints faced by individuals (op. cit., p. 88). ${ }^{17}$ In the following section, we will argue that the RP can be extended to 'back up' both the optimization assumption and the REH.

Nevertheless, such an operation will also highlight the uneasy relation between Popper's evolutionary theory of knowledge and learning and his RP.

\section{THE RATIONAL EXPECTATIONS HYPOTHESIS AND POPPER'S PHILOSOPHY}

The next question we address is whether, and if so, to what extent, the REH can be justified along the same lines as Popper defends his RP and, if so, whether this poses any further problems. As shown above, the RP is defined as an a priori methodological principle according to which we assume that our actions are adequate to our problem-situations as we see them (Popper, 1994, p. 181). However, if our actions are to be 'adequate', it is necessary that our expectations be 'correct' in the first place. That said, we can replace 'actions' by 'expectations' and, arguably, the RP would also become applicable to the REH. Further, we can tentatively accept as justifications of the REH, albeit adapted for the case at hand, the reasons that Popper (1985, p. 362) and Caldwell (1991, p. 25) offer in support of the RP: (i) the 'fertility' hypothesis and (ii) the 'elimination of arbitrariness' argument. When adapted to the REH, the former would imply that by 'blocking off' the possibility that economic agents make non-random mistakes and blaming instead other parts of the 'situational model' in case empirical tests happen to be negative, we can make more progress in our understanding of how economies work than doing otherwise. As to the latter, it could be argued that, by endogenizing the formation of expectations, the REH reduces the degree of arbitrariness in our model and improves mathematical tractability in the same way as the optimizing assumption does in neoclassical theory. ${ }^{18}$ As a result of it, advocates of the REH could argue that in the wake of an observed

\footnotetext{
${ }^{17}$ Becker (1976) apparently resorts to a similar argument to justify the use of the optimizing assumption to explain human behaviour. According to him, all human behaviour can be viewed from the standpoint of agents who maximize their utility from a stable set of preferences and subject to a given constraint. Where action appears to deviate from the predictions of utility theory, Becker claims that little is gained from resorting to explanations in terms of irrationality, changes in preferences or cultural values, etc... for such explanations are ad hoc and may even be contradictory.

${ }^{18}$ For instance, Krugman views the optimizing assumption as a modelling device rather than as a principle (Krugman, 1998, pp. 117 and ff). He argues that, other things being the same, it is always better to be able to derive behaviour from a maximization problem albeit he makes clear that we should not categorically deny the existence of types of behaviour that cannot be so derived. He admits that the reason he continues himself to assume optimizing behaviour in his own work is that it is very often the easiest way to build mathematical model of the phenomenon he is trying to understand (op. cit., p. 120). Gibbard and Varian (1978, p. 670) justify the optimizing assumption by arguing that the resulting behaviour can be expected to represent the 'central tendency' of human economic behaviour so long as optimization errors are not systematic.
} 
discrepancy between expected and realized outcomes they prefer, for strategic reasons, to ascribe the latter to the 'incorrectness' of a certain part of the 'situational model' than to the occurrence of systematic errors in the expectations formation mechanism.

Now, if the REH can, in principle, be justified on the same methodological basis as Popper's RP then, and to the extent that we concluded above that the REH is utterly incompatible with Popper's evolutionary theory of knowledge and learning, this could also be taken prima facie as an argument for the existence of an internal inconsistency in Popper's philosophy. This is a line of argument that we have pursued elsewhere but that we will not discuss here. Rather, the thesis we will explore is as follows: Popper's theory of knowledge and learning and his RP provide, when brought together, a meta-theoretical framework that can serve to evaluate the implications for economic theory and policy of the adoption of the REH. As we explain below, and as opposed to the advantages that the adoption of the REH may exhibit and that were discussed above, its adoption may also impart severe methodological 'biases' which may, in turn, result in potentially large socio-economic costs. In a nutshell, the meta-theoretical framework referred to above implies that the desirability of the adoption of the REH in economics hinges on whether its alleged benefits (fertility, decrease in modelling arbitrariness, and convenience) exceed its potentially large socio-economic costs.

\subsection{Methodological Biases}

The key ideas of Popper's evolutionary theory of knowledge and learning are that all knowledge is conjectural and that we acquire it through a process of trial and error-elimination.

Furthermore, Popper also argues that the process of adaptation to the surrounding environment is always imperfect in that some errors inevitably escape and that this is, arguably, the main reason we are all fallible. Finally, we have shown above that indeterminism, i.e., the notion that human behaviour is not pre-determined and that, hence, the future is open is an essential component of Popper's philosophy. We then argued that the REH violates these three hypotheses and concluded that the former is incompatible with Popper's theory of knowledge and learning. This conclusion is highly relevant to macroeconomists for the following reason: the REH necessarily precludes the exploration of the thesis that important malfunctions of market economies can be ascribed to economic agents' systematic errors in expectations formation. Specifically, and if the REH is adopted, such macroeconomic phenomena as 
financial crisis and large and recurrent fluctuations in aggregate output can only be ascribed to random forecast errors brought about by the occurrence of exogenous random shocks. For the sake of the argument, the business cycle theory proposed by Hyman Minsky $(1975,1982)$ based on overoptimistic expectations of economic agents about their ability to honour future cash commitments stemming from their inherited liability structure - must be ignored if we assume that agents' expectations are unbiased on average. By contrast, Minsky's theory accords with Popper's propositions that all knowledge is conjectural and that we 'learn' by testing our hypothesis and eliminating errors.

Let us dwell on the previous point. The language advocates of the REH employ is somewhat misleading. When they insist that economic agents do not make systematic mistakes, what they mean is that the economic system is hit randomly by 'exogenous' and, hence, unpredictable shocks. However, and crucially, if expectations are 'unbiased' on average then shocks can solely be 'exogenous' since, were they to be endogenously generated, economic agents should be able to foresee them. Further, the REH implies that agents' mistakes always occur after the shocks have hit the economy in the sense that they are 'caused' by them. Thus, the REH logically implies that economic agents never make any mistakes other than those caused by 'exogenous' shocks and, hence, the former can not be a source of instability. In this setting, macroeconomic fluctuations can only be engendered by factors 'external' to the economic system like, for instance, the government sector. By contrast, Minsky views business cycles as being 'endogenous' to capitalist economies. It is the simultaneous or highly coincident in time mistakes in the evaluation of their ability to honour future cash commitments by a certain proportion of market participants that leads them to get overleveraged in the upswing and which, in the wake of a worsening in profit expectations, leads to a sudden increase in liquidity preference which eventually triggers a massive asset price deflation. Therefore, it is endogenously generated and recurrent mistakes by economic agents that lie at the heart of business cycles in Minsky's approach. ${ }^{19}$ Such mistakes are recurrent and inevitable in the sense

\footnotetext{
${ }^{19}$ In the same vein, De Grauwe (2009) distinguishes between 'top-down' and 'bottom-up' systems. The former are systems where one or more agents fully understand the system, as in the models containing the REH. By contrast, he defines the latter as systems in which no individual understands the whole picture so that rationality consists of a trial-and-error selection process whereby agents assess the performance of the rules they are following and then decide whether to keep or change them depending on how well it performs relative to other rules. For our purposes, the key point is that he recognises that the application of the trial-and-error mechanism will result in a business cycle that has a large endogenous component. Similarly, Arthur (2013) associates endogenous fluctuations to 'nonequilibrium' when he writes:
} 
that economic agents formulate expectations in an environment characterized by 'uncertainty' in the sense of Keynes (1920) and Knight (1921). But 'uncertainty' is, arguably, the type of world implied by Popper's propositions that all our knowledge is conjectural, that our adaptation to the surrounding environment is always imperfect and that we 'learn' by trial and errorelimination. In other words, macroeconomic theories based on endogenous informational mistakes such as Minsky's are Popperian in body and soul; theories based on the random occurrence of 'exogenous' shocks such as those implied by the REH are not.

Next, and related to the previous point, if an economic theory is to be compatible with Popper's theory of knowledge and learning then it must be explicitly evolutionary. Several traditions in economics have adopted an evolutionary approach, examples being the American Institutionalist School of Veblen, Mitchel, and Commons, the Austrian School of Von Mises, Hayek, and Schumpeter and, more recently, the Evolutionary School (Nelson and Winter, 2002), Complexity Economics (Arthur, 2013), Imperfect Knowledge Economics (Frydman \& Golberg, 2007), and those Keynesians who endorse Minsky's interpretation of Keynes's General Theory (Minsky, 1975). It is beyond the scope of this paper to evaluate whether these approaches to economics are compatible with Popper's philosophy. However, let us note that in the abovementioned approaches it is the endless feedback process connecting conjectures, trials, discrepancies between expected and realized outcomes, elimination of errors, and generation of a new round of conjectures that provides the (internal) motion to the system.

Last, if the imposition of the REH onto economic models precludes the adoption of an evolutionary approach then, by reciprocity, the latter is also incompatible with the REH. To be sure, as the economy evolves over time, the 'true' model of the economy changes continuously and endlessly and, hence, economic agents can never manage to discover it. As we argued above, the recognition of the existence of hysteresis or path-dependency leads to a rejection of the REH insofar as economic agents' expectations, decisions, and actions will determine the future path of the economy. ${ }^{20}$ But, in a path-dependent economy it is the case that any acquired

\footnotetext{
'Nonequilibrium is the natural state of the economy... This isn't merely because of outside shocks or external influences, but because nonequilibrium arises endogenously in the economy. There are two reasons for this. One is fundamental (or Knightian) uncertainty, the other is technological innovation' (Arthur, 2013, p. 3, emphasis added).

${ }^{20}$ In this respect, Frydman and Golberg (2007) argue that if we really aim at building models that apply to modern economies, it is contradictory to adopt the REH since the latter implies that whatever change that occurs in the future is, by assumption, already known in the present and, therefore, economic change is predetermined. In turn, and with evident reminiscences of Shackle (1972), they add that this logically implies that there is no possibility for economic actors to 'create' the future.
} 
knowledge eventually expires since the structure and workings of the economy change continuously. In other words, the recognition that our expectations, decisions, and especially, actions determine the future path of the economy logically implies indeterminism and, hence, unpredictability as in Darwinian evolutionary biology.

\subsection{Socio-economic Costs}

The methodological 'biases' discussed above may ultimately impose large socio-economic costs upon society. As we argued above, the adoption of the REH logically implies that shocks are 'exogenous' to the system. In turn, this may preclude the study of those macroeconomic problems associated to coordination failures, economy-wide underestimation of investment risks, overoptimistic expectations, etc. The absence of these topics from the 'New Consensus in Macroeconomics' (hereafter NCM) may have stimulated the development of a conceptual framework that discourages the exploration of those phenomena precluded by the adoption of the REH since, as Popper (1972, p. 145) insists, 'facts are theory-laden'. For instance, in the wake of the economic and social damage caused by the financial crisis that erupted in the US in summer 2007, Buiter (2009) criticizes the NCM and concludes that:

'Both the New Classical and New Keynesian complete markets macroeconomic theories not only did not allow questions about insolvency and illiquidity to be answered. They did not allow such questions to be asked' (Buiter, 2009, p. 2).

He ascribes this dismal state of affairs to wrong methodological choices which made macroeconomists increasingly 'unfitted' to address real-world problems:

'Indeed the typical macroeconomics and monetary economics training received at Anglo-American universities during the last 30 years or so, may have set back by decades serious investigations of aggregate economic behaviour and economic policy relevant understanding. It was a privately and socially costly waste of time and other resources' (Buiter, 2009, p. 1, emphasis added).

In a similar vein, when answering the question 'how did economists get it so wrong?', Krugman (2009) attributes the academic failure to predict the outburst of the 2007 financial crisis in the US to, among other things, a preference by economists for mathematical beauty over social relevance and, specifically, to the deleterious influence of Panglossian Finance (after Dr. Pangloss in Voltaire's Candid) by which he refers to a combination of the 'Efficient Market 
Hypothesis' and the elegant 'Capital Asset Pricing Model' (see, also, Friedman, 2011). We may add to this that the pervasiveness of the REH in modern macroeconomic theory, with its assumption that economic agents only make random mistakes as the economy is hit by 'exogenous' shocks whose stochastic properties are fully pre-specified and, therefore, known to economic agents and policy-makers alike may have led - when coupled with the proposition that market economies are self-adjusting — to a preference by policy-makers for an institutional framework where: (i) macroeconomic policy is governed by fixed rules and (ii) an 'optimal' policy strategy is assumed to exist ${ }^{21}$.

By contrast, if Popper's hypotheses that all knowledge is conjectural, that our adaptation to the environment is imperfect, and that learning occurs through trial and error-elimination are taken on board, it becomes clear that any institutional framework is necessarily imperfect and there is no such thing as an 'optimal' policy. Arguably, the latter can only exist in an ergodic world where the future (or its statistical properties) is pre-determined and, hence, known by policy-makers. If we assume, instead, that future economic change is unknown and unknowable - as is implied by Popper's philosophy and Darwinian biology — then the notion of 'optimal' policy becomes contradictory. In this different scenario, current policy choices may affect the future evolution of the economic system in unpredictable ways. Further, in such scenario it is not possible to know in advance the nature of future economic change and, hence, the problems policy-makers will face in the future, so strict reliance on fixed rules encapsulated in a rigid institutional framework as the way to run macroeconomic policy may prove to be highly counterproductive. In other words, some discretion in macroeconomic policy and a flexible institutional framework that allows for a wider range of strategies in the wake of large macroeconomic fluctuations may be preferable in this scenario.

\section{SUMMARY AND CONCLUSIONS}

The REH is still the standard approach to expectations formation in mainstream macroeconomics. It implies that economic agents know the 'true' model of the economy which makes their expectations unbiased on average. Although many mainstream economists believe that the REH is a useful methodological device its epistemological status is still unclear. We

\footnotetext{
${ }^{21}$ The so-called 'policy ineffectiveness proposition' of Barro and Gordon (1983) is just one example of this. The absence of meaningful counter-cyclical fiscal policy at the federal and even national level in the euro-zone is another example.
} 
evaluated the REH in light of Popper's philosophy. First, we showed that it is largely incompatible with Popper's evolutionary theory of knowledge and learning as it violates three implications of the latter: (i) the conjectural character of all knowledge and, hence, its fallibility, (ii) its imperfect adaptation to the surrounding environment, and (iii) indeterminism. We then argued that the REH can be interpreted as a heuristic device aimed at facilitating the construction of better (or closer to the truth) models and that, in this sense, Popper's 'rationality principle' (RP) may come to its rescue. In particular, we argued that the arguments that have been offered in support of the RP can serve to justify the adoption of the REH. Notwithstanding it, we made it clear that if the REH is found to be at odds with the epistemological strand of Popper's philosophy but appears to be compatible with his RP this may, in principle, be due to the presence of an inconsistency in Popper's philosophy as much as to a weakness of the REH itself. No matter what our final diagnosis of this specific problem is, we argued that Popper's philosophy provides a meta-theoretical framework that can be used to evaluate the REH. Specifically, the REH can be viewed as a heuristic device aimed at reducing the arbitrariness in model building and facilitating mathematical tractability but, when confronted with Popper's theory of knowledge and learning, it emerges that it imparts a severe methodological bias on economic modelling. Specifically, by assuming that macroeconomic instability stems solely from 'exogenous' shocks that randomly hit the economy, it precludes the consideration of potential sources of inherent instability in the economy. Finally, we argued that, by implying the existence of an 'optimal' policy strategy that can be duly implemented if only policy-makers have the right incentives, the adoption of the REH favours the creation of an institutional framework that may be ill-suited to deal adequately with inherent sources of macroeconomic instability as, for instance, those identified in Minsky’s work. 


\section{REFERENCES}

Arrow, K. J. 1978. The Future and the Present in Economic Life, Economic Inquiry, 16(2), pp. 157-69.

1986. Rationality of self and others in an economic system, Journal of Business, 59(4.2): S385-S399.

Arthur, W. B. 2013. Complexity economics: a different framework for economic thought, Institute for New Economic Thinking Research Note \#033, March.

Barro, R. J. \& Gordon, D. B. 1983. Rules, Discretion and Reputation in a Model of Monetary Policy, Journal of Monetary Economics, 12(1), pp. 101-21.

Becker, G. 1962. Irrational behavior and economic theory, Journal of Political Economy, 70(1), pp. 1-13.

Boland, L. A. 2003. The Foundations of Economic Method: A Popperian Perspective, $2^{\text {nd }}$ edition, London: Routledge.

Bradie, M. 1986. Assessing Evolutionary Epistemology, Biology \& Philosophy, 1(4), pp. 40159.

Buiter, W. H. 2009. "The Unfortunate Uselessness of Most 'State of the Art' Academic Monetary Economics," www.blogs.ft.maverecon/2009/03/the-unfortunate-uselessnessof-most-state-of-the-art-academic-monetary-economics.

Caldwell, B. J. 1991. Clarifying Popper, Journal of Economic Literature, 29(1), pp. 1-33.

Crotty, J. R. 1994. Are Keynesian Uncertainty and Macrotheory Compatible? Conventional Decision Making, Institutional Structures, and Conditional Stability in Keynesian Macromodels, in G. Dymski and R. Pollin (eds.), New Perspectives in Monetary Macroeconomics, pp. 105-139, Ann Arbor: University of Michigan Press.

Davidson, P. 1991. Is Probability Theory Relevant for Uncertainty? A Post Keynesian Perspective, Journal of Economic Perspectives, 5(1), pp. 129-143.

De Grauwe, P. 2009. Top-down versus bottom-up macroeconomics, Paper presented at the conference "What is wrong with modern macroeconomics", CESifo, Munich, 6-7 November 2009.

Friedman, B. 2011. Reconstructing Economics in Light of the 2007-? Financial Crisis, Journal of Economic Education, 41(4), pp. 391-397.

Frydman, R. \& Goldberg, M. D. 2007. Imperfect Knowledge Economics, Princeton: Princeton University Press. 
Georgescu-Roegen, N. 1971. The Entropy Law and the Economic Process, Cambridge (MA): Harvard University Press.

Gibbard, A. \& Varian, H. R. (1978) Economic Models, Journal of Philosophy, 75(11), pp. 664677.

Hands, D. W. 1985. Karl Popper and Economic Methodology: A New Look, Economics and Philosophy, 1, pp. 83-99. 1992. Falsification, Situational Analysis and Scientific Research Programs: The Popperian Tradition in Economic Methodology, in de Marchi, N. (ed.) Post-Popperian Methodology of Economics: Recovering Practice, pp. 19-54, Boston: Kluwer Academic Publishers.

Hayek, F.A. 1937. Economics and Knowledge, Economica, 4(13), pp. 33-54.

Hume, D. 1748[2006]. An enquiry concerning human understanding: a critical edition, Oxford, Clarendon Press; New York : Oxford University Press.

Keynes, J. M. 1952[1920]. A Treatise on Probability, London: Macmillan.

Knight, F. H. 1971[1921]. Risk, Uncertainty, and Profit, Chicago: The University of Chicago Press.

Knudsen, C. 1993. Equilibrium, perfect rationality and the problem of self-reference in economics, in Mäki, U., Gustafsson, B. and Knudsen, C. (eds.) Rationality, Institutions and Economic Methodology, pp. 133-70, London: Routledge.

Koertge, N. 1975. Popper's Metaphysical Research Program for the Human Sciences, Inquiry, 18(4), pp. 437-62.

. 1979. The Methodological Status of Popper's Rationality Principle, Theory and Decision, 10(1/4), January, pp. 83-95.

Krugman, P. 1998 Rationales for Rationality, in Dennis, K. (ed.) Rationality in Economics: Alternative Perspectives, pp. 111-122, Boston: Kluwer Academic.

2009. How Did Economists Get It So Wrong? New York Times, September 6th.

http://www.nytimes.com/2009/09/06/magazine/06Economic-t.html?pagewanted=all\&_r=0

Loasby, B. J. 1999. Knowledge, Institutions and Evolution in Economics, London: Routledge.

Lucas, R. E. 1977. Understanding Business Cycles, in Brunner, K. and Meltzer, A.H. (eds.) Carnegie-Rochester Conference Series on Public Policy, Vol. 5, Stabilization of the Domestic and International Economy, pp. 7-29. 
1986. Adaptive behaviour and economic theory, in R. M. Hogarth and M. W. Reder (eds.) Rational Choice: The Contrast between Economics and Psychology, pp. 217-242, Chicago and London: University of Chicago Press.

Machlup, F. 1983. The Rationality of 'Rational Expectations', Kredit und Kapital, 16(2), pp. 172-83.

Minsky, H. P. 1975. John Maynard Keynes, New York: Columbia University Press.

. 1982. Can "It” Happen Again? Essays on Instability and Finance, Armonk (NY): M. E. Sharpe.

Muth, J.F. 1961. Rational Expectations and the Theory of Price Movements, Econometrica, 29(3), pp. 315-335.

Nelson, R. R. \& Winter, S. G. 2002. Evolutionary Theorizing in Economics, Journal of Economic Perspectives, 16(2), pp. 23-46.

Popper, K. R. 1963. Conjectures and Refutations: The Growth of Scientific Knowledge, London: Routledge and Kegan Paul.

1967. La rationalité et le statut du principe de rationalité, in E. M. Classen (ed.), Les Fondements Philosophiques des Systèmes Economiques, pp. 142-50, Paris: Payot.

. 1972. Objective Knowledge: An Evolutionary Approach, Oxford: Clarendon Press. 1976. Unended Quest, LaSalle, III: Open Court.

. 1985. The Rationality Principle, in D. Miller (ed.) Popper Selections, pp. 357-365, Princeton: Princeton University Press.

. 1990. A World of Propensities, Bristol (UK): Thoemmes.

. 1994. The Myth of the Framework: In defence of science and rationality, London: Routledge.

Samuelson, P. A. 1969. Classical and Neoclassical Theory, in Clower, R. W. (ed.), Monetary Theory, London: Penguin.

Sargent, T. J. 1993. Bounded Rationality in Macroeconomics, Oxford: Clarendon Press.

Savage, L. 1954. The Foundations of Statistics, New York: Wiley.

Shackle, G. L. S. 1972. Epistemics \& Economics: A critique of economics doctrines, Cambridge: Cambridge University Press.

Simon, H. A. 1976. From Substantive to Procedural Rationality, in Spiro J. Latsis (ed.) Method and Appraisal in Economics, pp. 129-148, Cambridge: Cambridge University Press. 
Soros, G. 2009. The Crash of 2008 and What it Means: The New Paradigm for Financial Markets, New York: Public Affairs.

Stiglitz, J. E. 2011. Rethinking Macroeconomics: What Failed, and How to Repair it, Journal of the European Economic Association, 9(4), pp. 591-645.

Tobin, J. 1981. The Monetarist Counterrevolution Today - An Appraisal, Economic Journal, 91(361), pp. 29-42.

Tversky, A. \& Kahneman, D. 1986. Rational choices and the Framing of Decisions, in R. M. Hogarth and M. W. Reder (eds.) Rational Choice: The Contrast between Economics and Psychology, pp. 67-94, Chicago and London: University of Chicago Press.

Volz, K. G. \& Gigerenzer, G. 2012. Cognitive processes in decisions under risk are not the same as in decisions under uncertainty, Frontiers in Neuroscience, 6(1), pp. 1-6.

Watkins, J. W. N. 1974. The Unity of Popper's Thought, in Schilpp, P. A. (ed.) The Philosophy of Karl Popper, pp. 371-412, Vol. XIV, Book I, LaSalle (IL): Open Court.

Woodford, M. 2009. Convergence in Macroeconomics: Elements of the New Synthesis, American Economic Journal: Macroeconomics, 1(1), pp. 267-279. 